\title{
THE MODEL FOR EVALUATION OF CORPORATE STRATEGIC CHANGES IN THE CONTEXT OF CLIMATE CHANGE: PLYWOOD MANUFACTURE
}

\author{
Andrius Tamošiūnas \\ Faculty of Business Management, Department of Social Economics and Management, Vilnius \\ Gediminas Technical University, Sauletekio al. 11, LT-10223 Vilnius, Lithuania \\ E-mail: andrius.tamosiunas@vgtu.lt.
}

Received 25 February 2013; accepted 30 April 2013

\begin{abstract}
The paper presents the model for evaluation of corporate management measures aimed at solving tasks related to climate change challenges (UN 1998; EP 2009; EC 2013) faced by enterprises and inevitably leading to corporate strategic changes. In a detailed yet concise manner, the paper analyses the model for evaluation of corporate strategic changes and specifies techniques for its application focusing on the following proposed criteria: the market share; financial capacity; business development potential; product competitiveness; and productivity.

The paper reveals the benefit of the use of the proposed model for corporate strategic changes. Greater possibilities are created to rationalise the process of corporate strategic changes and the use as well as development of human, material and financial potentials, which lead to greater competitiveness of an enterprise. The model guides to directions and actions to be taken in order to continue increasing effectiveness of an enterprise in the context of climate change objectives.

The evaluation model suggested by the author is also analysed according to flexibility of proposed techniques, the characteristics of which can be modified and adjusted depending on specifics of the changing business environment. This allows ensuring and promoting competitiveness of an enterprise while pursuing the climate change challenges (UN 1998; EP 2009; EC 2013) set for businesses.
\end{abstract}

Keywords: evaluation, strategic changes, climate change, carbon emissions trading scheme, all-round evaluation, product competitiveness, business development.

Reference to this paper should be made as follows: Tamošiūnas, A. 2014. The model for evaluation of corporate strategic changes in the context of climate change: plywood manufacture, Journal of Business Economics and Management 15(1): 135-152.

JEL classification: M11, M13, M21, M29.

\section{Introduction}

In market economy countries, corporate strategic changes are a continuous phenomenon. This natural process is stimulated by competition, market changes and processes of integration and globalisation of economic systems. They affect virtually all sectors of economic systems as to the increasing competition of business entities and their desire 
to maintain or strengthen positions in competitive markets on national or international scales.

Nevertheless, in addition to this context, the adopted United Nations Framework Convention on Climate Change (UN 1998) has set economic challenges for global economic systems for decades ahead. As a consequence, businesses have became increasingly engaged in rationalisation of the use of their human, material and financial resources aiming to reduce carbon ${ }^{1}$ emissions resulting from production intended to maintain and strengthen competitiveness.

The last decade of the economic system development has shown that corporate strategic changes in the context of climate change are a complicated task for enterprises, which is related to a great risk due to its essentiality and extent. Business entities are facing contradictions: short or mid-term success versus long term sustainable development; efficiency versus creativity; exploitation versus exploration; speed versus time-consuming resource building (Nonaka, Toyama 2002). Economic performance is influenced positively not only by the degree of diversification, for instance, but also by the ability of the company to increase its corporate coherence as the ability to generate and explore synergies of various types (Paulet 2008).

These factors reveal the necessity for complex improvement of the management of corporate strategic changes. It needs solutions, which would give a possibility to an enterprise, acting in the changing economic environment, to rationalise the management of the combination of its human, material and financial resources and other relevant strategic property thus increasing the competitiveness of an enterprise and reducing carbon emissions (UN 1998; EP 2009; EC 2013).

\section{Climate change and corporate strategic changes}

Physical impacts of climate change are already felt in most parts of the world. In the past decade, Europe has seen an increasing number of extreme weather events (Stern Review 2006). The EU Climate Change Policy is aimed at keeping the global warming below $2{ }^{\circ} \mathrm{C}$ compared to the temperature in pre-industrial times (EC 2009). This level is considered sufficient to reduce the probability of irreversible and extremely damaging effects but will not suffice to avoid a change in the currently experienced climatic conditions (UN 1998). A consensus is emerging that addressing climate change will require a cut in global greenhouse gas emissions of at least $50 \%$ by the middle of the century - considerably more in developed countries - which will have to bear the brunt of the abatement effort (EP 2009).

In this context, attention needs to be focused on Europe 2020 Strategy on smart, sustainable and inclusive growth and the Roadmap for moving to a competitive low carbon economy by 2050 (EC 2013), which establish the following three key climate change objectives mandatory for all EU Member States: reduce greenhouse gas emissions by

\footnotetext{
${ }^{1}$ Carbon unit - the greenhouse gas emission allowance; one carbon unit equals to one ton of emitted greenhouse gas.
} 
$20 \%$, increase the share of renewables in the EU energy mix to $20 \%$, and achieve a $20 \%$ improvement in energy efficiency by 2020 .

It is evident that in the light of increasing significance of climate change, enterprises will be required to adapt to changing regulatory frameworks - such as constraints on carbon emissions for sectors of energy production, car and aircraft manufacturing, construction, maritime and aviation as well as many other energy intensive industries; or the EU Emissions Trading Scheme ${ }^{2}$ (EU ETS; EC 2013) - all of which lead to strategic changes. Furthermore, three key climate change objectives mentioned above will represent at least $20 \%$ of EU spending in the period 2014-2020 and therefore be reflected in the appropriate instruments by each EU member state to ensure that they contribute to strengthen energy security, building a low-carbon, resource efficient and climate resilient economy that will enhance Europe's competitiveness and create more and greener jobs (EC 2013).

Without a doubt, actions needed to respond to climate change polices aimed at reduction of carbon emissions provide a clear direction for corporate strategic changes. Additionally, they offer many opportunities, for example, through early adoption of innovative new technology, which would place enterprises ahead of slower global competitors. Conversely, a failure to anticipate changes by business entities may lead to forced later adjustment, which could be damaging and leave them inadequately prepared. Climate change will act as a key factor for evolution of private and public enterprises (and organisations). Thus, senior management has to anticipate changes and meet the challenges. Furthermore, the imposed climate change measures (EC 2013) suppose a shared value approach (Porter, Kramer 2011), which should become a prerequisite for maintaining sustainable and effectively competitive business in such regulatory environment. To do so, enterprises will need to adapt their current products, processes and technology, and develop more innovative solutions. Respectively, the changes will imminently target the strategic management of enterprises.

Climate change factors (Tamošiūnas 2010) are affecting enterprises and there is a need for respective measures to be taken to fight against potential negative implications. Inevitably, this will entail corporate strategic changes.

As to the definition, it is important to emphasise that corporate strategic changes are subject to strategic management techniques used to rationalise the activity of an enterprise and resulting in essential changes of corporate strategy and structure in pursuit of the improvement of competitiveness in a clearly defined time outlook (Ginevičius et al. 2005; Wood 2009). Hence, the trade-off when the speed of corporate reconstruction is lower than the rate, at which environmental conditions change ${ }^{3}$ (Hannan, Freeman 1984) is not hallmarked. Furthermore, in this context, the theories of hubris (Roll 1986) and reputation (Scharfstein, Stein 2000), risk diversification (Amihud, Lev 1981), herd-

\footnotetext{
${ }^{2}$ A national allocation plan (NAP; EC 2013) sets greenhouse gas emission allowances for companies listed in the plan. If actual annual carbon emissions exceed the allowances, a company in question must purchase the respective amount of carbon units via EU ETS or elsewhere, otherwise it is subject to strict financial sanctions.

${ }^{3}$ Definition of organisational inertia.
} 
ing (Devenow, Welch 1996) and entrenchment (Shleifer, Vishny 1989) as well as excess liquidity (Jensen 2005) should be treated as factors magnifying (or at least subject to) agency issues and thus challenging the rationality of strategic changes but not justifying the need for strategic change. Therefore, precipitating factors (Meyer 1982), involved interpretive processes and the piecemeal as well as quantum change concepts (Miller, Friesen 1982) should be treated as contingency variables subject to substantiation tasks of the necessity for strategic changes. Of course, the concept of quantum changes - as featured by the attributes of corporate strategic changes set by definition stated above can be respected pro rata. Moreover, in this sense it is imperative to implement strategic changes relatively quickly to achieve better results (within two years, as the results start degrading when implementation of changes takes up to three years and even demonstrate the irrational propensity once these limits are exceeded; Miller, Friesen 1982; Kelly, Amburgey 1991; Jansen 2004; Beck, Bruderl 2008). Respectively, one of the essential tasks determining the purposeful management of corporate strategic changes is the objective evaluation of management measures and the results of their implementation.

Having this context in mind, the subsequent chapters propose solutions for the evaluation of corporate strategic changes as to achieve the goals of the relevant convergence of corporate strategic management and climate change.

\section{Model for the evaluation of the effectiveness of corporate strategic changes in the context of climate change}

No specific method for evaluation of the effectiveness of corporate strategic changes in the context of climate change objectives was found in literature. It was observed that usually ordinary methods for analysis and evaluation of effectiveness (while the concept of competitiveness is used often) of an enterprise activity are used. In this respect, literature presents a vast system of indicators (Rooij et al. 2011; Aebi et al. 2012). Having summarised possible indicators for evaluation of the effectiveness of corporate strategic changes aiming to pursue mandatory climate change objectives set out in para. 2, the following main criteria for the concerned evaluation are determined: market share; financial capacity; business development potential; product competitiveness; and enterprise productivity.

Basing upon the criteria stated above, the respective model is proposed, which generalised expression (see Eq. (1)) as follows:

$$
E_{R}=f\left(E_{1}, E_{2}, E_{3}, E_{4}, E_{5}\right) \geq E^{0}=f\left(E^{0}{ }_{1}, E^{0}{ }_{2}, E^{0}{ }_{3}, E^{0}{ }_{4}, E^{0}{ }_{5}\right),
$$

where $E_{R}$ - the benefit of corporate strategic changes (e.g., the respective programme and/or the action plan); $E_{1}$ - product competitiveness; $E_{2}$ - enterprise productivity; $E_{3}-$ market share; $E_{4}-$ business development potential; $E_{5}$ - financial capacity; $E_{1}^{0}{ }_{1}, E^{0}$, $E_{3}^{0}, E^{0}{ }_{4}, E^{0}{ }_{5}$ - indicators of product competitiveness, enterprise productivity, market share, business development potential, financial capacity of enterprise activity provided corporate strategic changes were not implemented; $E^{0}$ - enterprise activity effectiveness provided corporate strategic changes (e.g., the respective programme and/or the action plan) were not implemented. 
In the context of the model stated above, the calculated indicators for the enterprise with strategic changes are compared with the respective ones determined for the enterprise with no strategic changes (e.g., the respective programme and/or the action plan) implemented. Each component of the above model is detailed in the subsequent paragraphs to the level ensuring the practical application of the considered model.

\section{Product competitiveness}

Competitiveness is a capability of an enterprise to adapt - ensuring competitiveness of its product - to changing market conditions (Vives 2008; Thomke, Reinertsen 2012). In this respect, having analysed the research results of various scientists, the author of the paper proposes to express product competitiveness (see Eq. (2)) in the following manner:

$$
E_{1}=f\left(\gamma_{1}, \gamma_{2}, \gamma_{3}\right)
$$

where: $\gamma_{1}-$ the competitiveness indicator, $\gamma_{2}-$ the cumulative indicator of competitiveness of qualitative parameters, $\gamma_{3}$ - the cumulative indicator of competitiveness of product development, production and sales cost parameters all specified in this and the following paragraphs respectively.

Product competitiveness is a comparative indicator that shows the level of the specific demand satisfaction. This indicator is determined by comparison of competing products. A buyer prefers a product only if it has an advantage over other competitive products and ensures better satisfaction of customer demands.

The value of a product to a customer is determined by the complex of qualitative parameters, which are often grouped into "hard" and "soft" parameters:

- "hard" parameters define how a product functions describe the main characteristics and their conformity to national and international standards and norms including mandatory requirements for reduction of carbon emissions and increased use of renewable energy resources. In addition to respective regulatory sanctions for failure to comply with climate change objectives, noncompliance with these legally determined parameters can cause a loss of a market share (EC 2013);

- "soft" parameters characterise the aesthetic features such as design, colour and packaging.

As each "hard" parameter is determined by a specific value, no sophisticated evaluation is required. In order to evaluate 4 the conformity of "hard" parameters to the requirements of the standards and norms, the following competitiveness indicator is used (see Eq. (3)):

$$
\gamma_{1}=\prod_{k=1}^{m} g_{k} ;(k=1, \ldots, \mathrm{m}),
$$

where: $g_{k}$ - evaluation of the conformity of the "hard" parameter $k$ to requirements of standards and norms; $m$ - the number of "hard" parameters subject to analysis; $\gamma_{1}-$ the competitiveness indicator that shows the conformity of product parameters to requirements of standards and norms.

\footnotetext{
${ }^{4}$ Evaluation is based on points: e.g., 1 point for compliance and 0 points for noncompliance.
} 
"Soft" parameters have no physical measure; thus, their evaluation is subjective and based on product characteristics. For this reason, it is expedient to engage experts in evaluation of "soft" product parameters.

In terms of qualitative parameters, product competitiveness cannot be expressed using absolute values; thus, it is reasonable to use determined comparative values having compared analogous products (Aboulnasr et al. 2008). An analogous product has to belong to the same group of products as the considered product. The analogue has to be well-known in the market and its main parameters have to be investigated taking into account the specifics of the changing environment of the market.

As a comparative indicator, product competitiveness by each qualitative parameter can be expressed as follows (see Eq. (4)):

$$
\gamma_{i}=\chi_{i} / \chi_{i 0} ;(i=1, \ldots, n)
$$

where: $\gamma_{i}$ - the comparative indicator in case of the qualitative parameter $i ; \chi_{i}-$ value of the qualitative parameter $i$ of the analysed product; $\chi_{i 0}$ - value of the qualitative parameter $i$ of the analogous product; $n$ - the number of qualitative parameters subject to analysis.

Using the cumulative indicator of competitiveness, the conformity of the product price to customer requirements (which are set for the qualitative product parameters) can be evaluated. Calculating the cumulative indicator of competitiveness, it is necessary to determine the value of the qualitative parameter. This task can be performed by a group of experts, who know the product market well. The cumulative indicator of competitiveness of qualitative parameters $\left(\gamma_{2}\right)$ can be determined as follows (see Eq. (5)):

$$
\gamma_{2}=\sum_{i} \zeta_{i} \gamma_{i}
$$

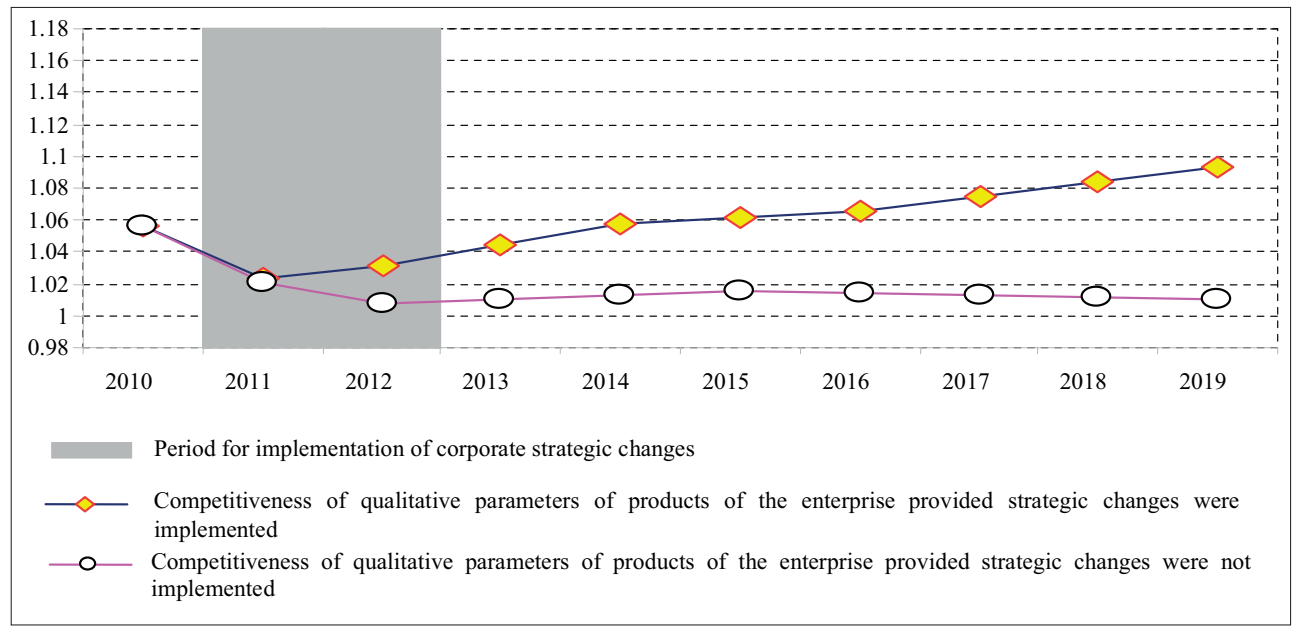

Fig. 1. Dynamics of the cumulative competitiveness index $\left(\gamma_{2}\right)$ of qualitative parameters of products manufactured by the enterprise 
where: $\zeta_{i}$ - the weight of the qualitative parameter $i ; \gamma_{i}$ - the comparative indicator in case of the qualitative parameter $i ; n$ - the number of qualitative parameters subject to analysis.

The product will be competitive under qualitative parameters if $\gamma_{2} \geq 1$.

Having made the analysis on the basis of indicators stated above and ascertained the qualitative competitiveness of products offered by a plywood producer $5,6,7,8$, strategic changes were introduced (with pivotal focus on reduction of carbon emissions and increase in the use of renewable energy). It was determined, that the aforementioned changes ensured a greater potential for the growth of the qualitative competitiveness of products (Fig. 1), which otherwise would not have been possible.

\footnotetext{
${ }^{5}$ A Latvian plywood producer was selected to justify the utility of practical application of the technique presented in this paper. The enterprise is the leader in the Baltic region and belongs to the top 5 of EU plywood market players with the current $18 \%$ of the market share and more than 2100 employees (this number increased by 100 since 2010 due to implemented changes). The author had a privilege to be consulting the enterprise in question on carbon portfolio issues (and test the model presented in this paper) since 2005. Subsequent strategic changes were implemented during the period of 2011-2012. Although the choice of the enterprise is rather arbitrary, the specified technique can be replicated with light adjustments (as per business category specifics) in every industry covered by EU ETS.
}

During the period 2011-2012, the key stages of plywood product manufacture - log delivery, storage, sorting and conditioning, log debarking and bucking, log heating, peeling of logs into veneers, drying and gluing of veneers, pressing of veneers in a hot press, plywood cutting, and sanding have been technologically upgraded automating the majority of operations and increasing the level of heterogeneity of product categories as well as the level of replication of operations per product category. While reducing energy consumed for manufacturing (from $230 \mathrm{kWh} / \mathrm{m}^{3}$ in 2010 to 170 $\mathrm{kWh} / \mathrm{m}^{3}$ (electrical) in 2012; from $6.0 \mathrm{GJ} / \mathrm{m}^{3}$ to $5.2 \mathrm{GJ} / \mathrm{m}^{3}$ (thermal) and from $41 / \mathrm{m}^{3}$ to $3.11 \mathrm{l} / \mathrm{m}^{3}$ (motor fuel)) of plywood and carbon emissions (from $410 \mathrm{~kg}$ to $320 \mathrm{~kg} \mathrm{per} \mathrm{m}^{3}$ of plywood produced), these improvements also made organisational structures more adaptive, which is similar to a switch between functional and product units to co-centric structures per customer specifics respectively reconfiguring the core resources and processes. Employees were trained and re-assigned new tasks or rotated focusing on the customer (product (category)-wise batch manufacturing). Due to increase in capacity resulting from individualised production (which also had a positive impact on plywood sale, which increased from 190 thou. $\mathrm{m}^{3}$ in 2010 to 220 thou. $\mathrm{m}^{3}$ in 2012), the corporate strategy was moved towards a more active participative entrenchment into business processes of customers.

${ }^{6}$ The strategic changes were implemented during a two-year period. This period of time was selected due to the following reasons: a) the specifics of enterprise, b) as per para. 2, various scientific sources stress the importance of a relatively rapid implementation of strategic changes to ensure better results.

${ }^{7}$ The seven-year forecasting period was chosen due to the following factors: a) due to specifics of activity, strategic plans of the enterprise cover the period from five to seven years, b) an average business cycle varies from 73 to 91 months (EC 2003, NBER 2010).

${ }^{8}$ In order to find the status quo to identify the impact of strategic changes on the business perspective of the enterprise, the conservative forecast was used throughout the paragraphs of this paper with the following key assumptions:

- the annual average rate of increase by $3 \%$ for expenditures categories basing upon the statistics of index of manufacturing producer prices (for Latvia) since 2009 (Eurostat 2013);

- the annual average rate of increase by $2 \%$ for categories of revenues basing upon the statistics of the harmonised index of consumer prices (lower figures of the EU were deliberately chosen instead of the Latvian ones) since 2009 (Eurostat 2013). 
When analysing the product competitiveness of the enterprise subsequent to strategic changes, it is necessary to evaluate the qualitative parameters of the product as well as the parameters of cost incurred in relation to product development, production and sales activities. These parameters reflect expenditures incurred by a customer following the purchase and use of the product within its lifetime. Values of parameters pertaining to development, production and sales cost of the product are determined on the basis of expenditures for the purchase $\left(C_{1}\right)$, shipment $\left(C_{2}\right)$, installation $\left(C_{3}\right)$, operation $\left(C_{4}\right)$, repair $\left(\mathrm{C}_{5}\right)$, personnel training $\left(C_{6}\right)$, insurance $\left(C_{7}\right)$, carbon emissions incurred $\left(C_{8}\right)$, renewable energy used (e.g.: solar, wind, water, bio-fuel; $C_{9}$ ), conventional energy used (e.g., fossil fuels: oil, rock-oil, coal; $C_{10}$ ) and etc. The following expression of expenditures (see Eq. (6)) shows the amount of funds required by a customer to have the product in operation for the entire lifetime period:

$$
C_{i}=\sum_{i} C_{i}
$$

where: $C_{i}$ - the price of consumption of parameter $i ; n-$ the number of parameters pertaining to development, production and sales cost of the product subject to analysis.

When calculating the comparative indicator of competitiveness by each parameter of product development, production and sales cost, the value of consumption expenditures for the customer can be corrected having compared the commercial conditions of the purchase and sales agreements of the considered product with the respective conditions of the analogous product. The comparative indicator of competitiveness by each parameter of product development, production and sales cost will be the following (see Eq. (7)):

$$
\gamma_{j}=\chi_{j} / \chi_{j 0}
$$

where: $\gamma_{j}$ - the comparative indicator of competitiveness under parameter $j$ of product development, production and sales cost; $\chi_{j}$ - the value of parameter $j$ of product development, production and sales cost; $\chi_{j 0}-$ the value of parameter $j$ of product development, production and sales cost of the analogous product.

Having calculated the indicators (with respect to each parameter) and evaluated the meaning of each of parameters pertaining to product development, production and sales cost, the cumulative indicator of competitiveness of product development, production and sales cost parameters can be calculated. The following expression (see Eq. (8)) is proposed:

$$
\gamma_{3}=\sum_{j} \zeta_{j} \gamma_{3},
$$

where: $\gamma_{3}$ - the cumulative indicator of competitiveness of product development, production and sales cost parameters; $\zeta_{j}$ - the weight of product development, production and sales cost parameter $j ; \gamma_{j}$ - the comparative indicator of competitiveness under parameter $j$ of product development, production and sales cost.

A product will be competitive under parameters of product development, production and sales cost if $\gamma_{3} \leq 1$. 
In the context of parameters of product development, production and sales cost (having calculated the cumulative indicator of competitiveness of product development, production and sales cost parameters), the future competitiveness potential of products manufactured by the analysed plywood producer subsequent to implemented strategic changes has a greater possibility for growth compared to the analogous product competitiveness indicator without implemented strategic changes (Fig. 2).

Basing upon the competitiveness indicator regarding the conformity of the product parameters to requirements of standards and norms as well as the cumulative competitiveness indicators of the qualitative and product development, production and sales cost parameters, it is possible to determine the (aggregated) product competitiveness indicator $\left(E_{1}\right)$ as follows (see Eq. (9)):

$$
E_{1}=\gamma_{3} \gamma_{1} / \gamma_{2}
$$

The product will be competitive when $E_{1} \geq 1$.

Basing upon competitiveness indicators pertaining to products manufactured by the enterprise and having evaluated the comparative effectiveness of the enterprise activity, the enterprise competitiveness indicator (see Eq. (10)) can be calculated in the following manner:

$$
E_{g}=\gamma_{g} E_{s}
$$

where: $E_{g}$ - the indicator of the enterprise competitiveness basing upon the competitiveness of products $g(g=1, \ldots, n) ; \gamma_{g}$ - the cumulative indicator of product competitiveness $\left(\gamma_{g}=\prod_{i=1}^{n} E_{g i}\right) ; E_{s}-$ the cumulative indicator of the comparative effectiveness of enterprise activity; this indicator can be calculated in this manner: $E_{s}=E_{3} E_{4}$ (para. 5); $n-$ the number of products subject to analysis.

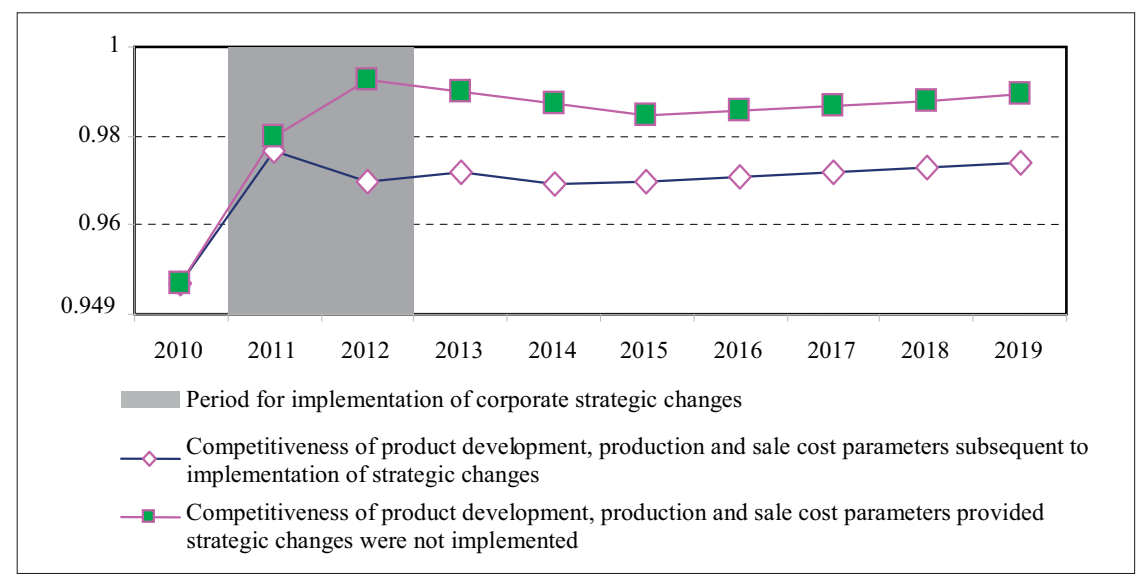

Fig. 2. Dynamics of the cumulative competitiveness index $\left(\gamma_{3}\right)$ of development, production and sales cost parameters of products manufactured by the enterprise 


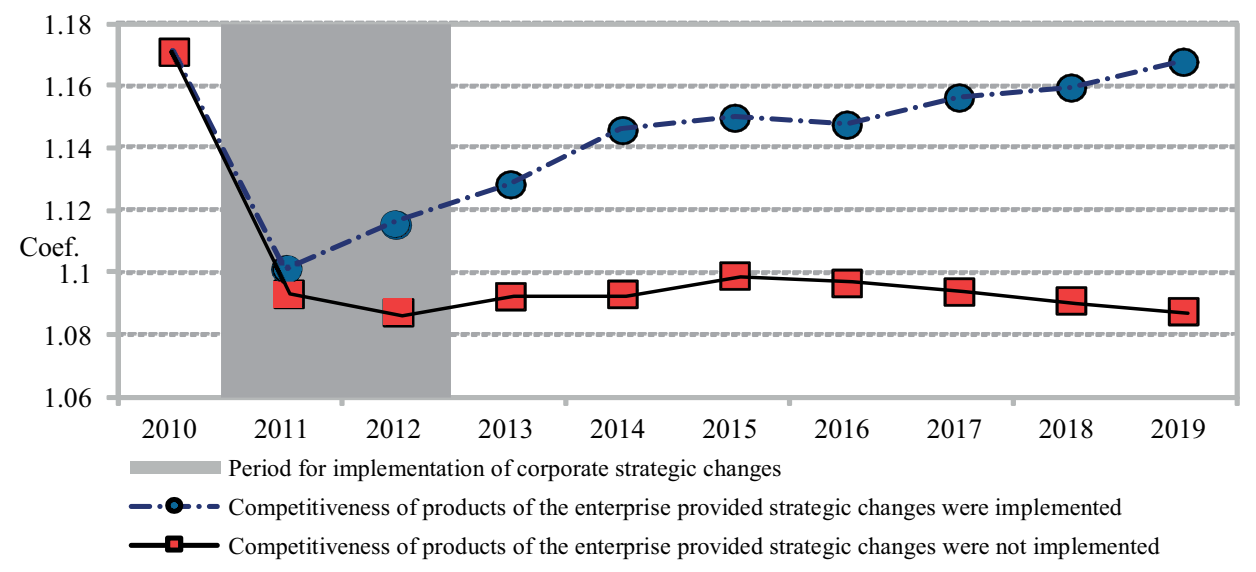

Fig. 3. Dynamics of the enterprise competitiveness

The cumulative indicator of the comparative effectiveness of the enterprise activity can be calculated applying various methods. To evaluate the comparative effectiveness of the considered enterprise activity, the position of products on the market is often compared with that of competing products. Respectively, market growth rate, operating profit, expenditures, profitability, and return on assets are compared.

Having used the technique specified above for calculations of the competitiveness of products manufactured by the plywood producer subsequent to implementation of strategic changes and having compared the results with the those of the enterprise without strategic changes, it was determined that possibilities of the plywood producer with to reach higher competitiveness of products are greater provided strategic changes were implemented (Fig. 3).

In the context of practical application of the model for evaluation of product competitiveness specified above, it is expedient to analyse the results of the use of this method with respect to the following aspects subject to the product competitiveness: the specialisation of manufacture, a threat of product cannibalisation, the consolidation of manufacture processes, a necessity to reform management systems, and the minimum sales volume necessary to justify the reformation of manufacture processes.

\section{Enterprise productivity, its market and business development potential}

Productivity of the enterprise (Saliola, Seker 2011; Syverson 2011) subsequent to implementation of strategic changes can be determined using the following expression (see Eq. (11)):

$$
E_{2}=f\left(\lambda_{1}, \lambda_{2}, \lambda_{3}\right),
$$

where: $\lambda_{1}=R / J$ - labour productivity; $R$ - sales in monetary terms; $J$ - the number of employees; 
$\lambda_{2}=R / T_{2}{ }^{a}$ - the return on assets; $T_{2}{ }^{a}$ - the value of active share of assets (production measures); $\lambda_{3}=R / C_{M}$ - the coefficient of return on materials used for production; $C_{M}$ - the cost of materials.

It is expedient to consider the results of productivity evaluation subsequent to implementation of strategic changes aimed at lower carbon emissions and increase in the use of renewable energy within the scope of the following factors: functionality, integrity and rationality of manufacturing processes, reasonability of organisational structure, knowledge, proficiency and motivation of workforce, its turnover.

The effect of implemented strategic changes on competitiveness, productivity and financial capacity of the enterprise also contributes to creation of market expansion possibilities as well as determines the potential for the development of activity of the enterprise (Epstein 2008; Hubbard 2009). In this respect, the market share of the enterprise subsequent to implementation of strategic changes could be calculated in the following manner (see Eq. (12)):

$$
E_{3}=R / R_{K}
$$

where: $R$ - product sales (market share) of the enterprise; $R_{K}$ - the total product sales in the market.

Having applied the Equation (12) to the example with the plywood producer subsequent to implementation of strategic changes aimed at reduction of carbon emissions and the increase in the use of renewable energy, it may be concluded that the increase in competitiveness of products manufactured by the enterprise as well as its productivity, which resulted from implementation of strategic changes, has contributed to growth of the market share of the enterprise. Without strategic changes aimed at lower carbon emissions and the increase in the use of renewable energy, possibilities of the enterprise to sustain and increase the market share would have been less attractive (Fig. 4).

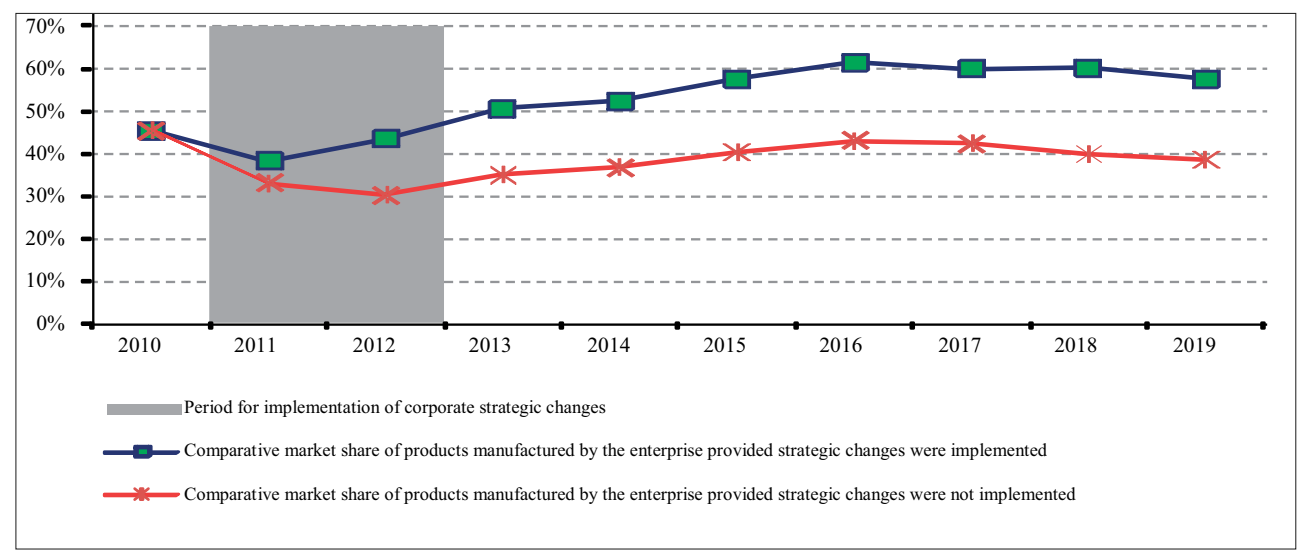

Fig. 4. Dynamics of the market share of products manufactured by the enterprise ${ }^{9}\left(E_{3}\right)$

\footnotetext{
${ }^{9}$ In the Baltic region.
} 
Despite the dynamics of the market share, the business development potential of the enterprise remains just as important. It is proposed to calculate the business development potential of the enterprise using this expression (see Eq. (13)):

$$
E_{4}=R_{t} / R_{0},
$$

where: $R_{t}$ - product sales for the considered period $(t=1, \ldots, n) ; R_{0}-$ product sales for the respective period in the past.

The business development potential of the enterprise as well as dynamics of its market share, notwithstanding the aspects stated in the previous paragraphs of this paper, are determined to a significant extent by the following factors: rationality of business network, specifics and the need of current and new business units.

\section{Financial capacity of the enterprise}

The financial capacity of an enterprise can be characterised by its financial stability and liquidity (Barth et al. 2012). In this context, the financial capacity of an enterprise (see Eq. (14)) could be expressed in the following manner:

$$
E_{5}=f\left(P, C, R, T_{1}, T_{2}, K, L\right)
$$

where: $P$ - the net profit; $C$ - costs of sales; $R$ - sales in monetary terms; $T_{1}-$ the working capital $\left(\mathrm{T}_{1}=T_{g}+T_{1}+A\right) ; T_{2}$ - long-term assets; $K$ - equity; $L$ - liabilities $(L=$ $\left.L_{2 s}+L+L_{2}\right)$.

Financial stability is the structure of the balance between assets, equity and liabilities of an enterprise, which ensures its solvency. Financial stability is ensured when investments into long-term assets and inventory do not exceed the amount of long-term financing sources (see Eq. (15)). It can be expressed as follows:

$$
T_{2}+A \leq K+L_{1},
$$

where: $T_{2}$ - long-term assets; $A$ - inventory; $K$ - equity; $L_{1}$ - long-term liabilities.

In order to evaluate the liquidity and financial stability of an enterprise, the indicators of revenue preservation and financial leverage are often applied in practice (Bikker 2010). Cash flow indicators (required to determine the conformity to financial leverage indicators; Xuan 2012) are sometimes used in practice as well. These indicators play a supplementary role when using the indicators of revenue preservation and financial leverage.

In the context of solvency, the financial capacity is ensured by rationally balancing the main short-term assets and short-term liabilities. It can be expressed in the following manner (see Eq. (16)):

$$
T_{\mathrm{g}}+T_{1} \geq L_{2},
$$

where: $T_{g}$ - cash in bank accounts and shares, stocks and other financial instruments of the money or capital markets; $T_{1}$ - receivables; $L_{2}$ - payables. 
Payables are calculated as follows (see Eq. (17)):

$$
L_{2}=L_{2 a}+L_{2 b}+L_{2 c}
$$

where: $L_{2 a}$, - obligations to suppliers; $L_{2 b}$ - other payables and short-term investments; $L_{2 c}$ - obligations regarding short-term loans, annual obligations to repay long-term loans.

The capacity of the enterprise to use short-term assets for covering all of the short-term liabilities is determined as enterprise liquidity. In order to execute the enterprise liquidity analysis and to ensure its precision, the following expression (see Eq. (18)) can be used (Fosberg 2012):

$$
W=\alpha T_{g}+\alpha T_{1}+\alpha A / \alpha L_{2 s}+\alpha L_{2}+\alpha L_{1},
$$

where: $A$ - inventory; $L_{2 s}$ - urgent liabilities; $L_{2}$ - short-term liabilities; $L_{1}-$ longterm liabilities; $\alpha$ - coefficient for corrections ${ }^{10}$ (in order to determine the comparative weight of the enterprise, liquidity values of coefficients are chosen taking into account the average statistical time periods for the execution of obligations towards assets and liabilities).

In order to ensure liquidity of the enterprise and reduce the risk, a part of equity has to be reserved for of short-term assets (working capital). Theoretically, the greater the own working capital, the lower is the liquidity risk; however, components of short-term assets have a different level of liquidity in practice (thus, coefficients $\alpha$ had to be used; Eq. (18)).

In the context of the considered plywood producer, due to the insufficient amount of short-term assets (provided strategic changes were implemented) the liquidity and profit possibilities decrease (Fig. 5). If there were no possibilities to increase the working capital faster than the amount of payables during a short-term period, modification of the structure of the balance of the enterprise assets, equity and liabilities is inevitable.

For instance, with respect to the plywood producer having implemented strategic changes, the share of short-term assets exceeding the short-term liabilities is projected (Fig. 5) while not decreasing the development scope of the enterprise activity, especially in profitable market segments; thus, possibilities to reduce liquidity risk of the enterprise and its business are greater compared to those without implementation of strategic changes.

Using the indicators stated in this paragraph, the following main indicators characterising the financial capacity of the considered plywood producer are calculated:

- revenues preservation - net profitability $(P / C)$, return on assets $\left(P / T_{2}\right)$, return on equity $(P / K)$;

- financial leverage indicators - the golden balance rule $\left(T_{2} /\left(K+L_{1}\right)\right)$, the net working capital $\left(\left(T_{1}-\left(L_{2 s}+L_{2}\right)\right) /\left(T_{2}+T_{1}\right)\right)$, the current liquidity ratio $(K / L)$, mobility $\left(T_{1} / K\right)$, the asset turnover $\left(R /\left(T_{2}+T_{1}\right)\right)$.

10 The coefficient in question allows hallmarking variables within the category and, thus, respectively contributes to more efficient liquidity management. 


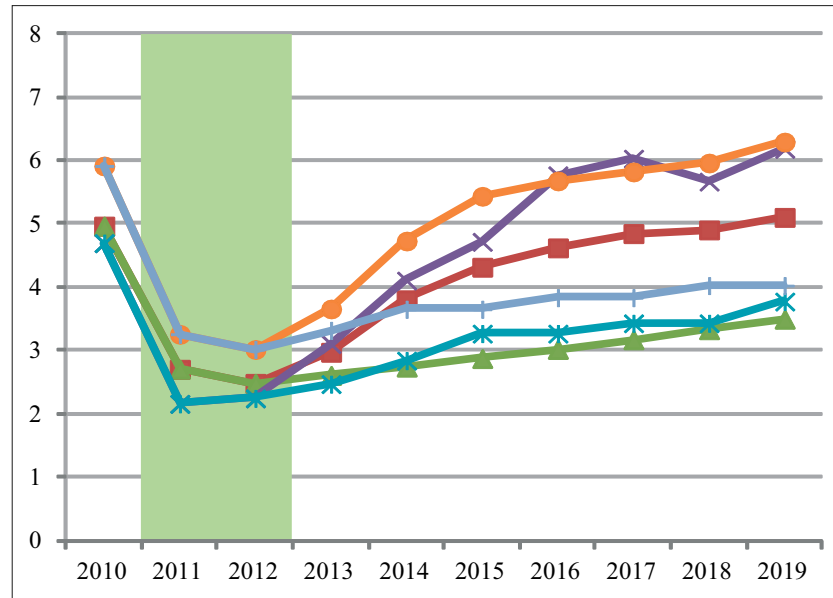

Period for implementation of
corporate strategic changes
Net profit of the enterprise provided
strategic changes were
implemented, $\%$.
Net profit of the enterprise provided
strategic changes were not
implemented, \%.
Return on assets of the enterprise
provided strategic changes were
implemented, $\%$.
Return on assets of the enterprise
provided strategic changes were not
implemented, $\%$.
Return on equity of the enterprise
provided strategic changes were
implemented, \%.
Return on equity of the enterprise
provided strategic changes were not
implemented, $\%$.

Fig. 5. Dynamics of indicators of enterprise revenue preservation

Having calculated the benefit of implemented strategic changes aimed at lower carbon emissions and the increase in the use of renewable energy by the plywood producer in terms of, e.g., revenue preservation, it was determined that this particular enterprise had a greater potential to reach a higher level of financial capacity provided the strategic changes were implemented (Fig. 5). A respective conclusion was also made as regards the comparison of financial leverage indicators of the enterprise provided strategic changes were implemented as well as for the case of the considered enterprise provided the strategic changes were not implemented (Figs 6, 7).

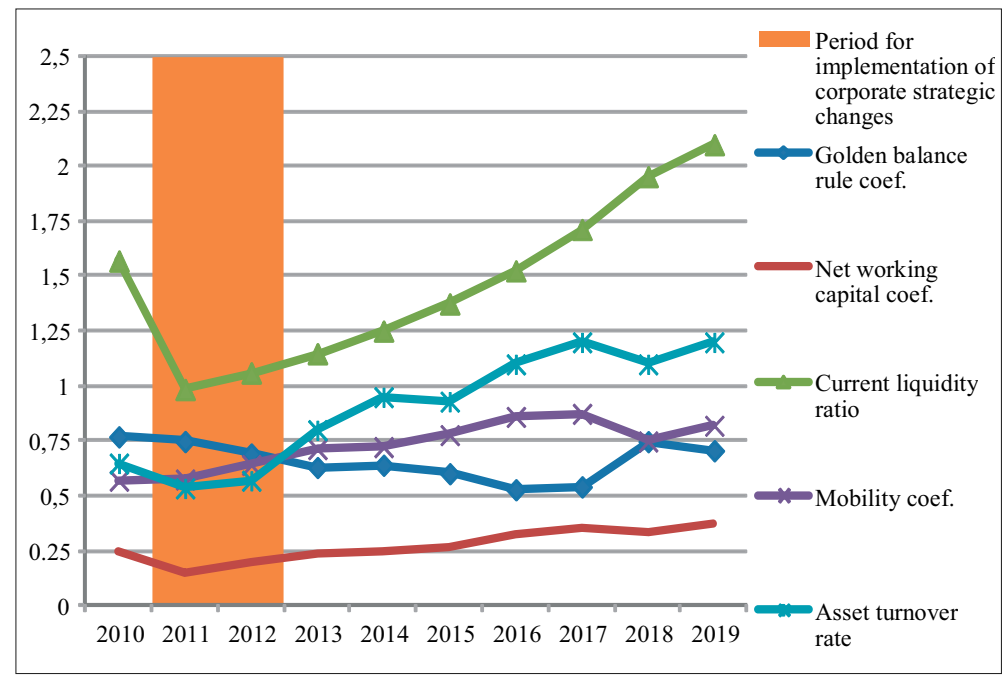

Fig. 6. Dynamics of financial leverage indicators of the enterprise provided strategic changes were implemented 


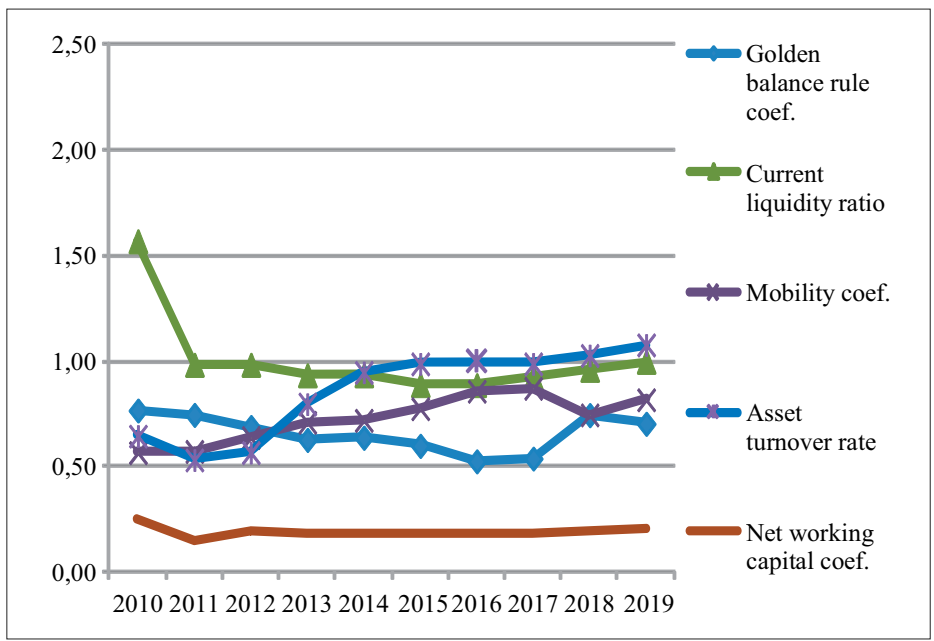

Fig. 7. Dynamics of financial leverage indicators of the enterprise provided strategic changes were not implemented

The results of application of the technique specified above show that it contributes to financial management of the enterprise when implementing strategic changes aimed at mandatory climate change objectives mentioned in para. 1 .

\section{Classification of evaluation results of corporate strategic changes}

It is proposed to use the classification of evaluation results (Table 1) when evaluating the effectiveness of corporate strategic changes using the above-described model.

Table 1. Classification of results achieved due to corporate strategic changes

\begin{tabular}{|c|c|c|}
\hline \multirow{9}{*}{ 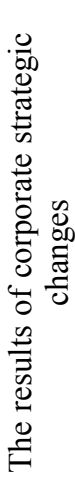 } & \multicolumn{2}{|c|}{ Level of benefit* of corporate strategic changes } \\
\hline & Unsatisfactory results & Satisfactory results \\
\hline & $E_{1}=E 0_{1} ; E_{2}>E 0_{2} ; E_{3}=E 0_{3} ; E_{4}=E 0_{4} ; E 5<E 0_{5}$ & $E_{1}>E 0_{1} ; E_{2}=E 0_{2} ; E_{3}=E 0_{3} ; E_{4}=E 0_{4} ; E 5<E 0_{5}$ \\
\hline & $E_{1}=E 0_{1} ; E_{2}=E 0_{2} ; E_{3}=E 0_{3} ; E_{4}>E 0_{4} ; E 5<E 0_{5}$ & $E_{1}=E 0_{1} ; E_{2}=E 0_{2} ; E_{3}>E 0_{3} ; E_{4}=E 0_{4} ; E 5<E 0_{5}$ \\
\hline & $E_{1}=E 0_{1} ; E_{2}=E 0_{2} ; E_{3}=E 0_{3} ; E_{4}=E 0_{4} ; E 5<E 0_{5}$ & $E_{1}>E 0_{1} ; E_{2}>E 0_{2} ; E_{3}>E 0_{3} ; E_{4}<E 0_{4} ; E 5<E 0_{5}$ \\
\hline & $E_{1}=E 0_{1} ; E_{2}=E 0_{2} ; E_{3}>E 0_{3} ; E_{4}<E 0_{4} ; E 5<E 0_{5}$ & $E_{1}>E 0_{1} ; E_{2}>E 0_{2} ; E_{3}>E 0_{3} ; E_{4}<E 0_{4} ; E 5<E 0_{5}$ \\
\hline & $E_{1}=E 0_{1} ; E_{2}>E 0_{2} ; E_{3}>E 0_{3} ; E_{4}<E 0_{4} ; E 5<E 0_{5}$ & $E_{1}>E 0_{1} ; E_{2}<E 0_{2} ; E_{3}>E 0_{3} ; E_{4}>E 0_{4} ; E 5<E 0_{5}$ \\
\hline & $E_{1}<E 0_{1} ; E_{2}>E 0_{2} ; E_{3}=E 0_{3} ; E_{4}>E 0_{4} ; E 5<E 0_{5}$ & $E_{1}=E 0_{1} ; E_{2}=E 0_{2} ; E_{3}=E 0_{3} ; E_{4}=E 0_{4} ; E 5>E 0_{5}$ \\
\hline & $E_{1}=E 0_{1} ; E_{2}<E 0_{2} ; E_{3}>E 0_{3} ; E_{4}>E 0_{4} ; E 5<E 0_{5}$ & $E_{1}=E 0_{1} ; E_{2}>E 0_{2} ; E_{3}=E 0_{3} ; E_{4}<E 0_{4} ; E 5>E 0_{5}$ \\
\hline
\end{tabular}

* The Table presents only levels of possible benefit of corporate strategic changes.

The proposed classification (Table 1) offers a possibility to determine the necessary minimal level of benefit of corporate strategic changes and evaluate the effectiveness of each enterprise management area. 


\section{Conclusions}

The prepared model for the evaluation of corporate strategic changes when pursuing climate change objectives (EC 2013) provides enterprises with the following possibilities:

- to measure the benefit of corporate strategic changes when reducing carbon emissions and increasing the use of renewable energy in the context of the following criteria: market share; financial capacity; business development potential; product competitiveness; and enterprise productivity;

- to evaluate the effectiveness of an enterprise, its development possibilities as well as viability of the corporate functional strategies with respect to its strategic, tactical and operational management levels in terms of the main characteristics of the enterprise and focusing on its competitive advantages.

The evaluation results derived basing upon the proposed model can also be used in the following respects:

- to improve the management of an enterprise increasing the effectiveness of independent business units as well as the functional departments of the enterprise;

- to rationalise the use of an enterprise human, material and financial resources determining making possibilities to attract the external resources to increase enterprise effectiveness and, thus, its competitiveness.

\section{References}

Aboulnasr, Kh.; Narasimhan, O.; Blair, E.; Chandy, R. 2008. Competitive response to radical product innovations, Journal of Marketing 72(3): 94-110. http://dx.doi.org/10.1509/jmkg.72.3.94 Aebi, V.; Sabato, G.; Schmid, M. 2012. Risk management, corporate governance, and bank performance in the financial crisis, Journal of Banking \& Finance 36(12): 3213-3226.

http://dx.doi.org/10.1016/j.jbankfin.2011.10.020

Amihud, Y.; Lew, B. 1981. Risk reduction as a managerial motive for conglomerate mergers, Bell Journal of Economics 12(2): 605-617. http://dx.doi.org/10.2307/3003575

Barth, M. E.; Landsman, W. R.; Lang, M.; Williams, C. 2012. Are IFRS-based and US GAAPbased accounting amounts comparable?, Journal of Accounting and Economics 54(1): 68-93. http://dx.doi.org/10.1016/j.jacceco.2012.03.001

Beck, N.; Bruderl, J. 2008. Momentum or deceleration? Theoretical and methodological reflections on the analysis or organizational change, Academy of Management Journal 51(3): 413-435. http://dx.doi.org/10.5465/AMJ.2008.32625943

Bikker, J. A. 2010. Measuring performance of banks: an assessment, Journal of Applied Business and Economics 11(4): 141-159.

Devenow, A.; Welch, I. 1996. Rational herding in financial economics, European Economic Review 40(3-5): 603-615. http://dx.doi.org/10.1016/0014-2921(95)00073-9

EC. 2003. Statistical Methods for Potential Output Estimation and Cycle Extraction. EC, Brussels. 65 p.

EC. 2009. White Paper. Adapting to Climate Change: Towards a European Framework for Action. Brussels. 16 p.

EP. 2009. Resolution of 31 January 2008 on the outcome of the Bali Conference on Climate Change (COP 13 and COP/MOP 3). OJ C 68 E, 21.3.2009: 13-17.

EC. 2013. Conclusions on Multiannual Financial Framework. No EUCO 37/13. 48 p. 
Epstein, M. 2008. Implementing corporate sustainability: measuring and managing social and environmental impacts, Strategic finance 89(7): 25-31.

Eurostat. 2013. Eurostat yearbook 2012. Eurostat. 692 p.

Fosberg, R. H. 2012. Capital structure and the financial crisis, Journal of Finance and Accountancy 11: 46-55.

Ginevičius, R.; Bivainis, J.; Tamošiūnas, A., et al. 2005. Modern Business: Development Priorities [Šiuolaikinis verslas: tobulinimo galimybès]. Collective Monograph. VGTU. Vilnius: Technika. 447 p. (in Lithuanian).

Hannan, M. T.; Freeman, J. 1984. Structural inertia and organizational change, American Sociological Review 49(2): 149-164. http://dx.doi.org/10.2307/2095567

Hubbard, G. 2009. Measuring organizational performance: beyond the triple bottom line, Business Strategy and the Environment 19(3): 177-191. http://dx.doi.org/10.1002/bse.564

Jansen, K. J. 2004. From persistence to pursuit: a longitudinal examination of momentum during the early stages of strategic change, Organization Science 15(3): 276-294.

http://dx.doi.org/10.1287/orsc.1040.0064

Jensen, M. C. 2005. Agency costs of overvalued equity, Financial Management 34(1): 5-19. http://dx.doi.org/10.1111/j.1755-053X.2005.tb00090.x

Kelly, D.; Amburgey, T. L. 1991. Organizational inertia and momentum: a dynamic model of strategic change, Academy of Management Journal 34(3): 591-612. http://dx.doi.org/10.2307/256407

Meyer, A. D. 1982. Adapting to environmental jolts, Administrative Science Quarterly 27(4): 515-537. http://dx.doi.org/10.2307/2392528

Miller, D.; Friesen, P. H. 1982. Structural change and performance: quantum versus piecemeal incremental approaches, Academy of Management Journal 25(4): 867-892.

http://dx.doi.org/10.2307/256104

NBER Business Cycle Dating Committee. 2010. National Bureau of Economic Research (NBER). US.

Nonaka, I.; Toyama, R. 2002. A firm as dialectical being: towards a dynamic theory of a firm, Industrial and Corporate Change 11(5): 995-1009. http://dx.doi.org/10.1093/icc/11.5.995

Paulet, E. 2008. Corporate governance for European small and medium size enterprises: an ambivalent concept on theoretical and empirical basis, Transformations in Business \& Economics 7(3): 207-218.

Porter, M.; Kramer, M. R. 2011. Creating shared value, Harvard Business Review 89(1/2): 62-77.

Roll, R. 1986. The hubris hypothesis of corporate takeovers, Journal of Business 59(2): 197-216. http://dx.doi.org/10.1086/296325

Rooij, van M.; Lusardi, A.; Alessie, R. 2011. Financial literacy and stock market participation, Journal of Financial Economics 101(2): 449-472.

Saliola, F.; Seker, M. 2011. Total factor productivity across the developing world, Enterprise Surveys. Enterprise Note 23, WB. 8 p.

Scharfstein, D. S.; Stein, J. C. 2000. Herd behavior and investment: reply, The American Economic Review 90(3): 705-706. http://dx.doi.org/10.1257/aer.90.3.705

Shleifer, A.; Vishny, R. W. 1989. Management entrenchment: the case of manager-specific investments, Journal of Financial Economics 25(1): 123-139.

http://dx.doi.org/10.1016/0304-405X(89)90099-8

Stern Review. 2006. The Economics of Climate Change. The UK Government, London. 662 p.

Syverson, Ch. 2011. What determines productivity?, Journal of Economic Literature 49(2): 326365. http://dx.doi.org/10.1257/jel.49.2.326 
Tamošiūnas, A. 2010. Managing corporate strategic changes in the context of climate change, Inzinerine ekonomika - Engineering Economics 21(1): 19-31.

Thomke, St.; Reinertsen, D. 2012. Six myths of product development, Harvard Business Review 90(5): 84-94.

UN. 1998. Kyoto Protocol to the United Nations Framework Convention on Climate Change. United Nations. $21 \mathrm{p}$.

Vives, X. 2008. Innovation and competitive pressure, Journal of Industrial Economics 56(3): 419-469.

Wood, A. 2009. Capacity rationalization and exit strategies, Strategic Management Journal 30(1): 25-44. http://dx.doi.org/10.1002/smj.725

Xuan, T. 2012. The role of venture capital syndication in value creation for entrepreneurial firms, Review of Finance 16(1): 245-283. http://dx.doi.org/10.1093/rof/rfr019

Andrius TAMOŠI ŪNAS is Associate Professor at the Department of Social Economics and Management, the Faculty of Business Management, Vilnius Gediminas Technical University (Lithuania). His scientific research refers to measures for management of processes pertaining to corporate strategic changes aimed at sustainable development of private and public sectors in the context of global economic cycle dynamics. Separate focus covers mega trends of climate change and renewable energy. 